\title{
Heterogeneous Nucleation Drives Particle Size Segregation in Sequential Ozone and Nitrate Radical Oxidation of Catechol
}

\author{
Lauren A. Garofalo,* Yicong He, Shantanu H. Jathar, Jeffrey R. Pierce, Carley D. Fredrickson, \\ Brett B. Palm, Joel A. Thornton, Fabian Mahrt, Giuseppe V. Crescenzo, Allan K. Bertram, \\ Danielle C. Draper, Juliane L. Fry, John Orlando, Xuan Zhang, and Delphine K. Farmer*
}

Cite This: Environ. Sci. Technol. 2021, 55, 15637-15645

Read Online

ACCESS | Lلll Metrics \& More | 回 Article Recommendations | st Supporting Information

ABSTRACT: Secondary organic aerosol formation via condensation of organic vapors onto existing aerosol transforms the chemical composition and size distribution of ambient aerosol, with implications for air quality and Earth's radiative balance. Gasto-particle conversion is generally thought to occur on a continuum

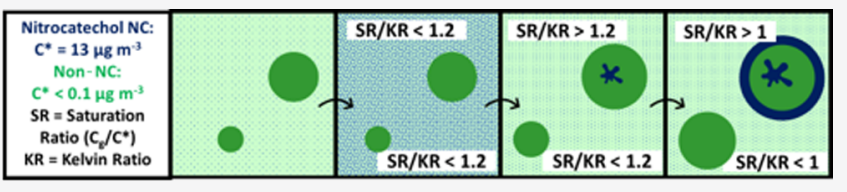
between equilibrium-driven partitioning of semivolatile molecules to the pre-existing mass size distribution and kinetic-driven condensation of low volatility molecules to the pre-existing surface area size distribution. However, we offer experimental evidence in contrast to this framework. When catechol is sequentially oxidized by $\mathrm{O}_{3}$ and $\mathrm{NO}_{3}$ in the presence of $\left(\mathrm{NH}_{4}\right)_{2} \mathrm{SO}_{4}$ seed particles with a single size mode, we observe a bimodal organic aerosol mass size distribution with two size modes of distinct chemical composition with nitrocatechol from $\mathrm{NO}_{3}$ oxidation preferentially condensing onto the large end of the pre-existing size distribution $(\sim 750 \mathrm{~nm})$. A size-resolved chemistry and microphysics model reproduces the evolution of the two distinct organic aerosol size modes-heterogeneous nucleation to an independent, nitrocatechol-rich aerosol phase.

KEYWORDS: atmospheric chemistry, aerosol microphysics, condensation, secondary organic aerosol

\section{INTRODUCTION}

The addition of secondary organic aerosol (SOA) from oxidation products of volatile organic compounds (VOCs) to pre-existing aerosol is controlled by thermodynamic equilibrium between the gas and particle phases. This process occurs between the limits of (1) equilibrium-driven net partitioning and (2) gas-phase diffusion-limited condensation, hereafter referred to as kinetic condensation, depending on the volatility of the condensing species. ${ }^{1-7}$ In the first limit, VOCs are oxidized to form semivolatile products that net partition to the particle phase in order to maintain equilibrium between the gas and particle phases. ${ }^{1}$ This equilibrium-driven condensation is controlled by Raoult's law and the Kelvin effect, and sizedependent condensation is roughly proportional to the existing mass or volume size distribution. In the second limit, VOCs are oxidized to form low-volatility products that irreversibly condense onto existing particles. ${ }^{4}$ This kinetic condensation depends on the collision rate, and size-dependent condensation is roughly proportionally to the existing Fuchs-corrected surface area size distribution. ${ }^{4,8}$ The relative contribution of these two condensation methods, including kinetic limitations in equilibrium net partitioning, occurs on a continuum with these two condensation schemes as limits, impacting the final aerosol size distribution and chemical composition. A special case to consider is the initial condensation of low-volatility species to the surface area, followed by saturation, evaporation, and re-condensation to larger particle sizes. ${ }^{4}$ Through these processes, the properties of the existing SOA affect the rates ${ }^{5-7}$ and yields ${ }^{9}$ of SOA production.

Though generally not considered for organic vapors condensing onto organic aerosol (OA), we hypothesize a third mechanism for gas-to-particle conversion-heterogeneous nucleation, in which a new phase forms on pre-existing particles. Condensation of organic vapors to a new phase is frequently observed in the condensation of organic vapors to existing inorganic aerosol or ions when heterogeneous nucleation is energetically favored over homogeneous nucleation. ${ }^{10}$ However, to the best of our knowledge, heterogeneous nucleation of semivolatile organic vapors in the presence of pre-existing OA has not yet been documented. This process represents a previously unconsidered pathway for SOA formation in the atmosphere that impacts aerosol size distributions, with implications for aerosol radiative and health effects, as well as atmospheric lifetime. Of more direct relevance is the consideration of heterogeneous nucleation in the experimental design of SOA laboratory studies of mixed

Received: $\quad$ May 7, 2021

Revised: November 2, 2021

Accepted: November 11, 2021

Published: November 23, 2021 
oxidants and/or VOCs. Here, we present an experiment with the likely development of a heterogeneously nucleated aerosol phase with an independent chemical composition.

Wildfires emit a complex mixture of trace gases and particles that are chemically processed (oxidized) in plumes. Biomass burning directly emits catechol (1,2-dihydroxybenzene; $\left.\mathrm{C}_{6} \mathrm{H}_{6} \mathrm{O}_{2}\right)^{11,12}$ and produces catechol through the oxidation of phenol. ${ }^{13,14}$ Oxidation of catechol by $\mathrm{NO}_{3}, \mathrm{OH}$, and $\mathrm{O}_{3}$, the major tropospheric oxidants, yields lower volatility species that can either homogeneously nucleate to form new particles or condense onto existing particles, to contribute to SOA mass. Catechol oxidation by $\mathrm{NO}_{3}$, relevant at night or in optically dense plumes, forms 4-nitrocatechol (1,2-dihydroxy-4-nitrobenzene; $\left.\mathrm{C}_{6} \mathrm{H}_{5} \mathrm{NO}_{4}\right)$ at a near-unity molar yield $(0.91 \pm 0.06)$; catechol oxidized by $\mathrm{OH}$ in the presence of $\mathrm{NO}_{x}$ also makes nitrocatechol but at a molar yield of only $0.30 \pm 0.03$, along with additional condensable products. ${ }^{15}$ Even in a particle-rich environment such as a smoke plume, SOA produced from VOC precursors can change the chemical, physical, and optical properties of the existing aerosol; nitrocatechol has an outsized impact on aerosol absorption in wildfire smoke plumes for its mass ${ }^{16}$ and more strongly absorbs solar radiation compared to the $\mathrm{NO}_{3}$ oxidation products of other phenolic species. ${ }^{17}$ Unique to catechol among other oxygenated aromatics (e.g., phenol, guaiacol, and cresol), ozonolysis of catechol forms $\mathrm{SOA}$; the ozonolysis reaction is still slow $\left(k_{\text {Catechol }+\mathrm{O}_{3}}=13.5 \times\right.$ $10^{-18}$ ) but is accelerated compared to the other listed species due to the two adjacent $\mathrm{OH}$ groups sharing the electron density through the conjugated bonds. ${ }^{18,19}$ The ozonolysis reaction produces many condensable products including ringopened species. However, most studies have investigated this reaction in the condensed phase or at the air-surface interface, and exact gas-phase mechanisms and kinetics are poorly understood. Quantum calculations of homogeneous ozonolysis found that the catechol $+\mathrm{O}_{3}$ reaction rate is 6 orders of magnitude slower than the experimental values, perhaps due to wall reactions in the chamber studies that actually produce $\mathrm{OH}$ that forms SOA, on which heterogeneous ozonolysis occurs on the surface of that existing SOA. ${ }^{20}$ The mechanism by which SOA is initially formed is not important to the proposed heterogeneous nucleation mechanism here. Experimental gasphase reaction rates and SOA yields are summarized in Figure 1.

Here, we investigate the size-resolved chemical composition of SOA formed from the sequential $\mathrm{O}_{3}$ and $\mathrm{NO}_{3}$ oxidation of catechol in the presence of ammonium sulfate seed. We compare the mass size distributions with results from $\mathrm{OH}$ oxidation of catechol in the presence of $\mathrm{NO}_{x}$. For the $\mathrm{O}_{3}+$ $\mathrm{NO}_{3}$ experiment only, we observe the unexpected formation of a larger size mode composed of only nitrocatechol that is independent of the pre-existing seed aerosol or additional $\mathrm{O}_{3}$ derived SOA. We employ a size-resolved chemistry and microphysics model to test the hypothesis that heterogeneous nucleation drives the condensation of nitrocatechol to an independent size mode rather than to the existing surface area or mass size distribution. We additionally show evidence of similar bimodal size distributions in the oxidation of $\Delta$-carene by $\mathrm{O}_{3}$ and $\mathrm{NO}_{3}$, which suggests that this heterogeneous nucleation mechanism may be broadly relevant. (a)

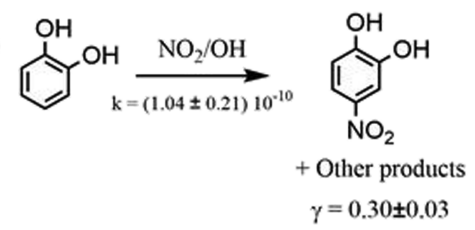

(b)

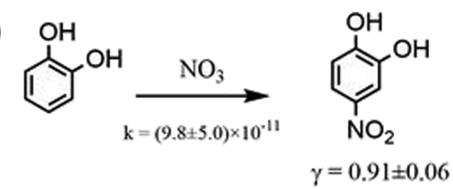

(c)

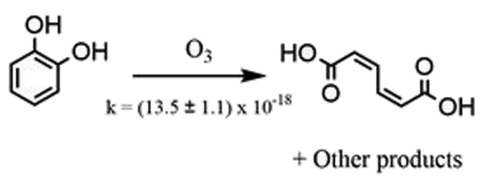

Figure 1. Reaction rate constants $\left(\mathrm{OH}_{;}{ }^{21} \mathrm{NO}_{3}{ }^{22}\right.$ and $\left.\mathrm{O}_{3}{ }^{23}\right)$ and aerosol molar yield ${ }^{15}$ for the relevant reactions in this experiment.

\section{METHODS}

The Monoterpene and Oxygenated aromatic Oxidation at Night and under LIGHTs (MOONLIGHT) project was a series of chamber studies to investigate the oxidation of select VOCs under elevated $\mathrm{NO}_{x}$ conditions relevant to wildfire smoke chemistry. Studied VOCs included (a) phenolic compounds (phenol, catechol, guaiacol, and cresol), (b) furfural, and (c) monoterpenes (a-pinene, limonene). These VOCs were oxidized by (i) $\mathrm{OH}$ in the presence of $\mathrm{NO}_{x}$ or (ii) $\mathrm{NO}_{3}$ radicals formed by the reaction of $\mathrm{O}_{3}$ with $\mathrm{NO}_{2}$ in the absence of light. $\mathrm{OH}$ was produced via the photolysis of $\mathrm{H}_{2} \mathrm{O}_{2}$ and/or HONO under high $\mathrm{NO}_{x}$ conditions. Each experiment was performed in the presence of dry AS $\left(\mathrm{NH}_{4}\right)_{2} \mathrm{SO}_{4}$ seed particles to inhibit new particle formation and reduce condensation of OA onto the chamber walls.

Details about the National Center for Atmospheric Research (NCAR) Atmospheric Simulation Chamber and each experiment are given in the Supporting Information. Briefly, for the catechol $+\mathrm{O}_{3}+\mathrm{NO}_{3}$ experiments, ozone and catechol were added into the chamber, followed by $\left(\mathrm{NH}_{4}\right)_{2} \mathrm{SO}_{4}$ particles (AS seed), allowing time for mixing between injections. After a period of mixing, $\mathrm{NO}_{2}$ was added and the experiments ran for $>4 \mathrm{~h}$. The reaction of $\mathrm{NO}_{2}+\mathrm{O}_{3}$ makes $\mathrm{NO}_{3}$ - the original target oxidant for this experiment. For the catechol $+\mathrm{OH} / \mathrm{NO}_{x}$ experiments, $\mathrm{HONO}$ was added to the chamber, followed by catechol and $\left(\mathrm{NH}_{4}\right)_{2} \mathrm{SO}_{4}$ particles. After an additional waiting period, the UV lights were turned on and the experiment ran for approximately $6 \mathrm{~h}$.

Relevant measurements included particle size and composition by high-resolution aerosol mass spectrometry (AMS), particle size by a scanning mobility particle sizer (SMPS), speciated organic gas and particle concentrations by iodideadduct ionization with a chemical ionization mass spectrometry with a filter inlet for gas and aerosol (FIGAERO-CIMS), and oxidant measurements $\left(\mathrm{O}_{3}\right.$ and $\left.\mathrm{NO}_{2}\right)$ by $\mathrm{UV}$ absorption and chemiluminescence, respectively. Detailed descriptions of instruments are given in the Supporting Information.

\section{RESULTS AND DISCUSSION}

Chamber Experiments. The time series of gas and particle species for the sequential oxidation of catechol by $\mathrm{O}_{3}$ and $\mathrm{NO}_{3}$ in the NCAR $10 \mathrm{~m}^{3}$ environmental chamber initially appear to be consistent with that of a typical SOA experiment 
(Figure 2). $\mathrm{O}_{3}$ and $\mathrm{NO}_{2}$ reagents were repeatedly injected, as evident by multiple sharp increases in mixing ratios, as shown
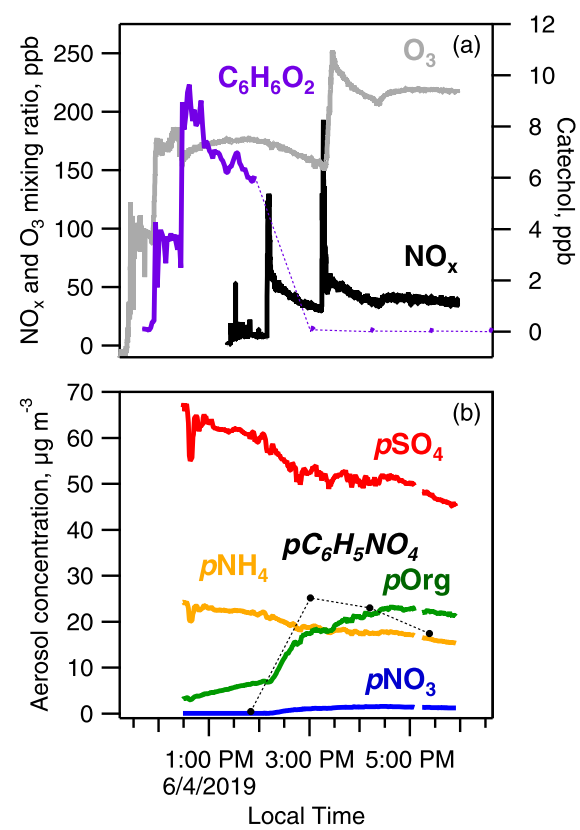

Figure 2. Time series of (a) gas-phase mixing ratios $\left[\mathrm{O}_{3}, \mathrm{NO}_{x}\right.$, and $\left.\mathrm{C}_{6} \mathrm{H}_{6} \mathrm{O}_{2}\right]$ and (b) bulk speciated aerosol mass concentrations from the AMS and nitrocatechol mass from the FIGAERO-CIMS for catechol $+\mathrm{O}_{3}+\mathrm{NO}_{3}$ chamber experiment. Red and yellow traces are $p \mathrm{SO}_{4}$ and $p \mathrm{NH}_{4}$, respectively, from the AS seed particles; the green trace is organic ( $p \mathrm{Org}$ ). The black trace shows particulate nitrocatechol as measured by the FIGAERO-CIMS. The AMS measures a smaller size range and thus smaller particulate mass than the FIGAERO-CIMS. The blue trace, $p \mathrm{NO}_{3}$, is also associated with nitroaromatic products. We note that (1) we did not correct for particle wall loss and (2) we modified the sampling cycle of the FIGAERO-CIMS when SOA formation began causing discontinuities in $\mathrm{C}_{6} \mathrm{H}_{6} \mathrm{O}_{2}$ and $p \mathrm{C}_{6} \mathrm{H}_{5} \mathrm{NO}_{4}$ (connected by a dashed line).

in Figure 2a, in order to maintain excess $\mathrm{NO}_{3}$. A highresolution aerosol mass spectrometer measured the sizeresolved aerosol chemical composition, as shown in Figure 2b. The AMS began sampling $\sim 30 \mathrm{~min}$ after catechol $\left(\mathrm{C}_{6} \mathrm{H}_{6} \mathrm{O}_{2}\right), \mathrm{O}_{3}$, and ammonium sulfate (AS) seed particles were added to the chamber, observing an initial OA mass concentration of $5 \mu \mathrm{g} \mathrm{m}^{-3}$ (labeled $p$ Org in Figure 2). OA increased steadily until $\mathrm{NO}_{2}$ was added to produce $\mathrm{NO}_{3}$ ( 2:15 PM), at which time the SOA formation accelerated. Catechol was rapidly consumed and nitrocatechol $\left(p \mathrm{C}_{6} \mathrm{H}_{5} \mathrm{NO}_{4}\right)$ was produced upon the introduction of $\mathrm{NO}_{2}$; both species were measured by FIGAERO-CIMS. A particlephase sample prior to $\mathrm{NO}_{2}$ addition shows zero nitrocatechol contribution while the AMS shows non-zero OA mass. The FIGAERO-CIMS has two modes of operation: continuous gasphase measurement or discontinuous simultaneous gas measurement and particle collection on a filter, interspersed with the measurement of particles by thermal desorption. Before nitrocatechol production, the FIGAERO-CIMS continuously measured gas-phase catechol $\left(\mathrm{C}_{6} \mathrm{H}_{6} \mathrm{O}_{2}\right)$, but the sampling cycle was changed to sample particles after nitrocatechol production. This change caused discontinuities in the gas-phase catechol and particle-phase nitrocatechol time series, and the rapid decline of catechol due to its reaction with $\mathrm{NO}_{3}$ and production of nitrocatechol was not observed with high time resolution. The AMS measures a smaller size range compared to the FIGAERO-CIMS, so the nitrocatechol mass measured by the FIGAERO-CIMS is greater than OA measured by the AMS. (See the Supporting Information for further discussion.) Regardless, these observations of $\mathrm{OA}$, particle-phase nitrocatechol, and gas-phase catechol indicate that catechol reacts with both ozone and $\mathrm{NO}_{3}$ to produce SOA, but ozonolysis produces $\mathrm{SOA}$ at a slower rate than $\mathrm{NO}_{3}$ oxidation.

While the time series of bulk particle composition implies standard SOA production upon the oxidation of catechol, the chemically speciated particle size distributions show that SOA unexpectedly separated into two distinct size modes as the $\mathrm{NO}_{3}$ oxidation progresses. These results do not match the previously considered limits controlling gas-to-particle conversion: kinetic condensation to pre-existing surface area distribution or ideal equilibrium partitioning to pre-existing mass distribution. The size distributions of the bulk chemical species and individual high-resolution mass spectrum ions at maximum OA concentrations are shown in Figure 3. The AS seed, while not monodisperse, shows a monomodal size
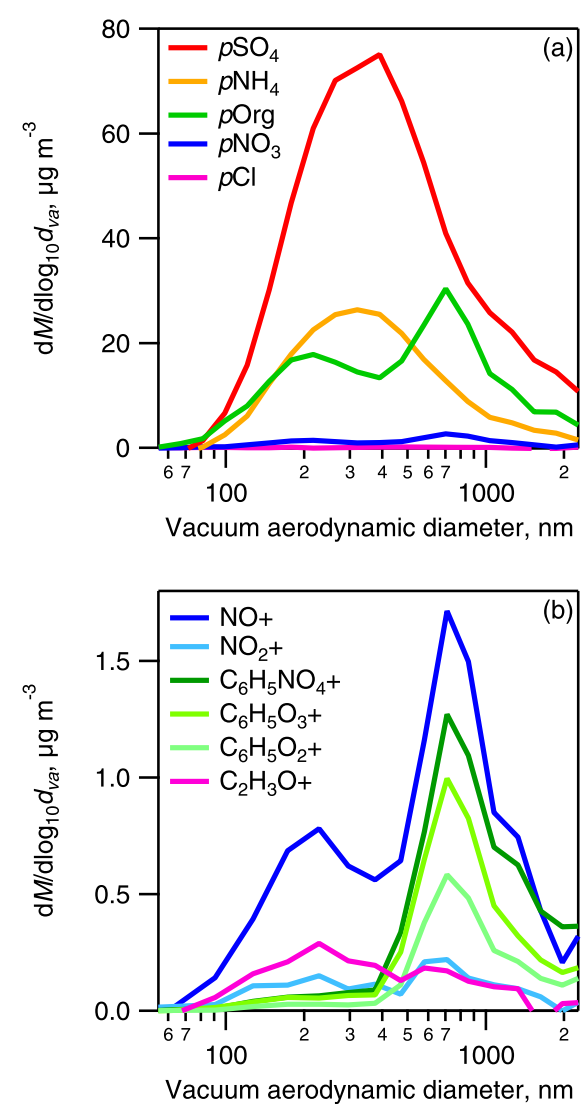

Figure 3. Particle size distribution for catechol $+\mathrm{O}_{3}+\mathrm{NO}_{3}$ oxidation during peak OA concentration (4 Jun 2019; 3:30-4:30 PM) for (a) bulk chemical species and (b) selected high-resolution ions: $\mathrm{pNO}_{3}$ components $\left(\mathrm{NO}^{+}, \mathrm{NO}_{2}^{+}\right)$; the nitrocatechol molecular ion and fragment ions $\left(\mathrm{C}_{6} \mathrm{H}_{5} \mathrm{NO}_{4}^{+}, \mathrm{C}_{6} \mathrm{H}_{5} \mathrm{O}_{3}{ }^{+}\right.$, and $\left.\mathrm{C}_{6} \mathrm{H}_{5} \mathrm{O}_{2}{ }^{+}\right)$; and a smaller oxidized organic fragment $\left(\mathrm{C}_{2} \mathrm{H}_{3} \mathrm{O}^{+}\right)$. The nitrocatechol molecular and fragment ions are almost exclusively in the larger size mode centered at $d_{\mathrm{va}}=750 \mathrm{~nm}$, and absent in the smaller mode at $d_{\mathrm{va}}=250$ $\mathrm{nm}$. $\mathrm{NO}^{+}$and $\mathrm{NO}_{2}{ }^{+}$are present in both modes but more prevalent in the larger mode with a larger $\mathrm{NO}^{+} / \mathrm{NO}_{2}{ }^{+}$ratio, consistent with nitroaromatics in the larger mode and organic nitrates in the smaller mode. 
distribution with maximum mass at vacuum aerodynamic diameter $d_{\mathrm{va}}=350 \mathrm{~nm}$ (Figure 3a). Meanwhile, $p$ Org is bimodal - with a smaller mode centered at $250 \mathrm{~nm}$ and a larger mode centered at $750 \mathrm{~nm}$. The shift of the $250 \mathrm{~nm}$ OA mode to slightly smaller diameters compared to the AS is consistent with kinetic condensation to the Fuchs-corrected surface area, implying that the volatility of this condensing SOA is low. The smaller mode increased in mass both during the catechol ozonolysis and after catechol was depleted. The larger mode was absent before the $\mathrm{NO}_{2}$ injection (Figure $\mathrm{S} 1$ ) and only formed as $\mathrm{NO}_{2}$ reacted with $\mathrm{O}_{3}$ to form $\mathrm{NO}_{3}$. In the size distributions of individual high-resolution ions (Figure $3 \mathrm{~b}$ ), we find that the nitrocatechol molecular ion $\left(\mathrm{C}_{6} \mathrm{H}_{5} \mathrm{NO}_{4}^{+} ; \mathrm{m} / z\right.$ 155.11) and electron ionization fragments $\left(\mathrm{C}_{6} \mathrm{H}_{5} \mathrm{O}_{3}{ }^{+} ; \mathrm{m} / z\right.$ 125.10, $\mathrm{C}_{6} \mathrm{H}_{5} \mathrm{O}_{2}{ }^{+} ; \mathrm{m} / z$ 109.10) appear almost exclusively in the larger mode. In contrast, the OA in the smaller mode is dominated by organic fragments more typical for ozonolysis $\mathrm{SOA}$-for example, $\mathrm{C}_{2} \mathrm{H}_{3} \mathrm{O}^{+}(\mathrm{m} / z$ 43.04). This $\mathrm{OA}$ comes from both the ozonolysis of catechol as well as ozone or nitrate oxidation of the uncondensed products from the ozonolysis of catechol. We will call the sum of these products "nonnitrocatechol (nonNC)" SOA.

The majority of signal in the FIGAERO-CIMS particle mass spectra comes from nitrocatechol, and individual ozonolysis products are not observed in substantive quantities-though we note that the AMS clearly observes these ozonolysis products. The latter are observed as increases in $p$ Org prior to the production of $\mathrm{NO}_{3}$ (Figure $2 \mathrm{~b}$ ). The question remains whether this discrepancy is due to relative insensitivity of the iodide reagent ion to ozonolysis products or due to the multitude of unknown (and thus challenging to quantify) ozonolysis products that, individually, do not appear significant compared to the dominant $\mathrm{NO}_{3}$ oxidation product nitrocatechol.

One interesting result of this experiment is the apparent contribution of nitroaromatic species to the $\mathrm{NO}_{3}$ signal in the AMS. While there are no significant sources of inorganic nitrate in these chamber studies, $p \mathrm{NO}_{3}=2.2 \mu \mathrm{g} \mathrm{m}^{-3}$ at the maximum $\mathrm{OA}$ signal, indicating that nitrocatechol likely fragments to $\mathrm{NO}^{+}$and $\mathrm{NO}_{2}{ }^{+}$and contributes to $p \mathrm{NO}_{3}$, similar to contributions of organic nitrates to $\mathrm{pNO}_{3}$ observed in chamber-generated and ambient aerosol. ${ }^{24}$ This apparent increase in $\mathrm{NNO}_{3}$ coincides in time (Figure 2) with the formation of nitrocatechol SOA. The size distribution (Figure 3a) also shows that both size modes contain particulate nitrate $\left(p \mathrm{NO}_{3}\right)$-but with distinct $\mathrm{NO}^{+}$and $\mathrm{NO}_{2}^{+}$fragmentation patterns. The ratio of $\mathrm{NO}^{+}$to $\mathrm{NO}_{2}{ }^{+}$in the AMS are often used to distinguish organic nitrate $\left(\mathrm{RONO}_{2}\right)$ from inorganic nitrate (e.g., $\left.\mathrm{NH}_{4} \mathrm{NO}_{3}\right)^{24}$ However, the electron ionization mass spectra of nitroaromatics $\left(\mathrm{RNO}_{2}\right.$, where $\mathrm{R}$ is a phenyl group) also contain $\mathrm{NO}^{+}$and $\mathrm{NO}_{2}{ }^{+}$ions. The two size modes contain distinct $\mathrm{NO}^{+} / \mathrm{NO}_{2}{ }^{+}$ratios; $\sim 4$ and $\sim 8$ in the smaller and larger modes, respectively. Farmer et al. ${ }^{24}$ reported an average $\mathrm{NO}^{+} /$ $\mathrm{NO}_{2}{ }^{+}$of $3.5 \pm 0.3$ with a range of $1.8 \pm 0.5$ and $4.6 \pm 0.2$ for a variety of organic nitrate standards. We also note that $\mathrm{NO}^{+} /$ $\mathrm{NO}_{2}{ }^{+}$ratios of $\sim 10$ have been reported for organic nitrates made from monoterpenes. ${ }^{25,26}$ The apparent non-zero contribution of nitrocatechol to the AMS $\mathrm{NNO}_{3}$ and the $\mathrm{NO}^{+} / \mathrm{NO}_{2}^{+}$of the various oxidation products may complicate the use of the $\mathrm{NO}^{+} / \mathrm{NO}_{2}{ }^{+}$in quantifying the contribution of organic nitrogen (both as organic nitrate and organic nitro compounds) to $\mathrm{pNO}_{3}$ in environments with significant amounts of nitro compounds.
The developing bifurcation of the size distribution and formation of two chemically distinct modes is apparent in the time series of the size-resolved ions (Figure 4). Nitrocatechol
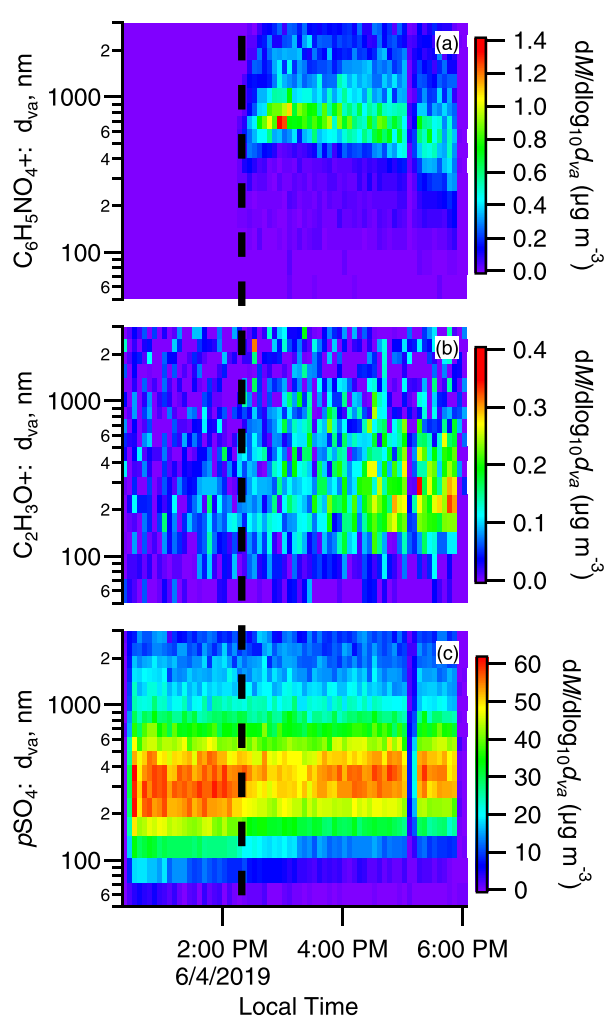

Figure 4. Time series of size distributions for the molecular ion of nitrocatechol $\left(\mathrm{C}_{6} \mathrm{H}_{5} \mathrm{NO}_{4}{ }^{+} ; \mathrm{a}\right)$, fragment of oxidized organics $\left(\mathrm{C}_{2} \mathrm{H}_{3} \mathrm{O}^{+} ; \mathrm{b}\right)$, and seed particles $\left(p \mathrm{SO}_{4} ; \mathrm{c}\right)$ for the catechol $+\mathrm{O}_{3}+$ $\mathrm{NO}_{3}$ sequential oxidation experiment. Brighter colors indicate a higher concentration $\left(\mathrm{d} M / \mathrm{dlog} d_{\mathrm{va}} \mu \mathrm{g} \mathrm{m}^{-3}\right)$ scaled to appropriate ranges for each species. The dashed line indicates $\mathrm{NO}_{2}$ addition.

appears rapidly after the $\mathrm{NO}_{2}$ addition and quickly grows to $750 \mathrm{~nm}$ in $<30 \mathrm{~min}$ and stabilizes at that size once catechol is depleted. After the lights are turned on at 5:20 PM, the particles containing nitrocatechol shrink, likely due to photolysis, evaporation, and particle wall loss. The time series of $\mathrm{C}_{2} \mathrm{H}_{3} \mathrm{O}^{+}$shows that the oxidized species condensed onto the existing seed particles throughout the experiment, dominating the smaller mode. The seed particles containing $\mathrm{pSO}_{4}$ do not substantively change size over the course of this experiment except for a small shift to larger sizes-consistent with condensational growth without seed coagulation. While we might anticipate a distinct mode of pSO4 in the larger sizes as nitrocatechol condenses onto seed particles, the $\mathrm{pSO}_{4}$ data are inconclusive. The net effect is that the mean diameter of $\mathrm{pSO}_{4}$ seed shifts to slightly larger sizes throughout the experiment but does not show clear bifurcation. We note that the observed bifurcation of SOA occurs consistently across replicate catechol $+\mathrm{O}_{3}+\mathrm{NO}_{3}$ experiments, with similar results in three separate experiments, and does not occur for the catechol $+\mathrm{OH}$ and other phenolics $+\mathrm{O}_{3}+\mathrm{NO}_{3}$ experiments.

These bimodal distributions are validated by the SMPS data (Figure S2). Unfortunately, the SMPS only scanned electrical mobility diameters between 24 and $457 \mathrm{~nm}$. The vacuum aerodynamic diameter measured and reported by the AMS is equal to the electrical mobility diameter multiplied by the 
particle density and shape factor. ${ }^{27}$ For example, for the larger mode, a vacuum aerodynamic diameter of $750 \mathrm{~nm}$ corresponds to a mobility diameter of $\sim 424 \mathrm{~nm}$ if the particle is pure AS (density $=1.77 \mathrm{~g} \mathrm{~cm}^{-3}$; shape factor $=1$ ). If a particle is completely composed of organic species with a density of $1.4 \mathrm{~g}$ $\mathrm{cm}^{-3}$, the $750 \mathrm{~nm}$ vacuum aerodynamic diameter corresponds to a mobility diameter of $536 \mathrm{~nm}$. Thus, SMPS could not observe the peak of the larger size mode (centered between 424 and $536 \mathrm{~nm}$ mobility diameter) well. Nevertheless, we observe a larger mode growing in the largest SMPS bin immediately after nitrocatechol is first formed (Figure S2), consistent with the AMS results in Figure 4.

In contrast to the bimodal distribution in the catechol $+\mathrm{O}_{3}$ $+\mathrm{NO}_{3}$ experiment, oxidation of catechol by $\mathrm{OH}$ in the presence of $\mathrm{NO}_{x}$ shows only a single mode of OA-no bimodal distribution (Figure S3). The oxidation of catechol by $\mathrm{OH} / \mathrm{NO}_{x}$ also produces nitrocatechol but with a smaller molar yield of $0.30 \pm 0.03$, and a higher diversity of SOA products. ${ }^{15}$ The OA mode, made of nitrocatechol and other organic species, co-condensed onto the surface area of the AS seed particles, so the organic mass size distribution is shifted to slightly smaller sizes than the AS (Figure S3a), consistent with kinetic condensation to the Fuchs-corrected surface area. The size distributions of nitrocatechol and $\mathrm{C}_{2} \mathrm{H}_{3} \mathrm{O}^{+}$are congruent, indicating that nitrocatechol and other SOA products have condensed onto the same size mode (Figure S3b). Consistent with the lower molar yield and additional oxidation products, nitrocatechol does not dominate the oxidation products in the $\mathrm{OH} / \mathrm{NO}_{x}$ experiments. Like the catechol $+\mathrm{OH} / \mathrm{NO}_{x}$ experiments, SOA formed during the sequential $\mathrm{O}_{3}+\mathrm{NO}_{3}$ oxidation of other aromatic compounds (phenol, guaiacol, and cresol) maintains a monomodal distribution (not shown). For experiments other than the sequential catechol $+\mathrm{O}_{3}+\mathrm{NO}_{3}$ experiment, condensable gases formed by oxidation reactions evenly distribute to particles across the AS surface area size distribution, again consistent with kinetic condensation to the Fuchs-corrected surface area. The reaction rate constants of $\mathrm{O}_{3}$ with phenol, guaiacol, and cresol are much smaller than that with catechol, eliminating the apparently confounding factor of pre-existing OA from ozonolysis.

Overall, our results demonstrate that nitrocatechol formation and condensation to the particle phase from sequential $\mathrm{O}_{3}$ and $\mathrm{NO}_{3}$ oxidation drives the development of a bimodal size distribution. In the larger nitrocatechol-dominated size mode, there is scant evidence in the mass spectra of molecules other than nitrocatechol beyond the initial AS seed and small amounts of OA from the initial ozonolysis SOA. In parallel, little nitrocatechol net partitions to the particles comprising the smaller mode (Figure 4). That is, once nitrocatechol begins to condense onto particles, additional nitrocatechol favors net condensation onto particles that already contain nitrocatechol. To explain the behavior observed in the sequential $\mathrm{O}_{3}$ and $\mathrm{NO}_{3}$ oxidation of catechol experiments, we hypothesize that a thermodynamic (activity) or possibly kinetic (particle-phase diffusivity) barrier prevents newly formed nitrocatechol vapors (from the oxidation of catechol with $\mathrm{NO}_{3}$ ) from condensing onto or mixing with the existing particles that contain the already-formed ozone SOA. In this hypothesis, the nitrocatechol mode is formed by heterogeneous nucleation of a nitrocatechol aerosol phase on top of the existing ozone SOA or uncoated seed in the presence of ozone SOA-although a small amount of $p$ Org and ozonolysis SOA markers are observed at larger sizes before $\mathrm{NO}_{2}$ addition (Figure S1). The thermodynamic or kinetic barrier allows nitrocatechol vapor concentration to accumulate until it is supersaturated with respect to pure nitrocatechol. Once this supersaturation hits a nucleation threshold, the new phase is formed on the existing particles. Because smaller particles have an additional Kelvin (curvature) barrier, the nucleation threshold is achieved at lower supersaturations for the larger particles relative to the smaller particles. Once the larger particles have nucleated, condensation to these particles balances the chemical production of nitrocatechol, and the supersaturations required to nucleate on smaller particles are never achieved, which creates the two distinct particle size modes with the nitrocatechol limited to the larger mode.

Model Studies. To investigate the heterogeneousnucleation hypothesis described above, we used a state-ofthe-science OA model. SOM-TOMAS, an amalgamation of the statistical oxidation model (SOM) and the TwO Moment Aerosol Sectional (TOMAS) model, uses a carbon-oxygen grid and a two-moment sectional size-distribution scheme to represent the oxidation chemistry, thermodynamic properties, and microphysics of SOA. Details for the SOM-TOMAS model can be found in previous publications noting that it has been recently used to study SOA formation from biomass burning emissions, ${ }^{28}$ biogenic VOCs, ${ }^{29}$ and unburned fuels. ${ }^{30}$ Below and in the Supporting Information, we provide details pertaining to the modeling undertaken here.

SOA formation following the addition of $\mathrm{NO}_{2}$ to the chamber was simulated using three model species: $\mathrm{O}_{3}-\mathrm{SOA}$, NC-SOA, and non-NC-SOA. O $\mathrm{O}_{3}$-SOA represented the ozonolysis products of catechol prior to $\mathrm{NO}_{2}$ addition at $t=$ 0 in the model. NC-SOA represented the nitrocatechol formed from the reaction of catechol with $\mathrm{NO}_{3}$, while non-NC-SOA was a lumped species that represented all oxidation products formed from multigenerational species reaction with $\mathrm{O}_{3}$ under the presence of $\mathrm{NO} / \mathrm{NO}_{2}$ or $\mathrm{NO}_{3}$. NC-SOA was assigned a saturation concentration $\left(C^{*}\right)$ of $13 \mu \mathrm{g} \mathrm{m}^{-313}$ and $\mathrm{O}_{3}$-SOA and non-NC-SOA was assumed to be nearly non-volatile $\left(C^{*}\right.$ $=10^{-6} \mu \mathrm{g} \mathrm{m}^{-3}$. Results are insensitive to $C^{*}$ as high as $10^{-2} \mu \mathrm{g}$ $\left.\mathrm{m}^{-3}\right)$. Formation rates and time periods for these gas-phase species were optimized until the model predictions of NCSOA and non-NC-SOA in the particle phase matched the corresponding AMS measurements. The AMS measurements were estimated by apportioning the total measured SOA signal with the following two mass fragments: NC-SOA $=\mathrm{C}_{6} \mathrm{H}_{5} \mathrm{NO}_{4}^{+}$ $(\mathrm{m} / z 155.022)$ and non-NC-SOA $=\mathrm{C}_{4} \mathrm{H}_{4} \mathrm{O}_{2}{ }^{+}(\mathrm{m} / z$ 84.021) These suggested that the NC-SOA was preferentially formed after the $\mathrm{NO}_{2}$ addition and subsequent non-NC-SOA was formed from uncondensed products from catechol oxidation by $\mathrm{O}_{3}$ once catechol was depleted.

The kinetic condensation of non-NC-SOA to the existing $\mathrm{OA}$ (i.e., SOA formed prior to the addition of $\mathrm{NO}_{2}$ ) was modeled using absorptive partitioning theory. ${ }^{1,2}$ A similar approach to model NC-SOA did not reproduce the characteristic bimodal mass size distributions from the experiment (Figure S4). Instead, we assumed that the NC-SOA heterogeneously nucleated as a separate phase onto the existing aerosol. The heterogeneous nucleation was modeled using the following function: $F_{\mathrm{act}, j}=\operatorname{sigmoid}\left(\frac{\mathrm{SR}_{j}-A}{B}\right)$, where $F_{\text {act, } j}$ is the fraction of particles activated in size bin $j, S R_{\mathrm{j}}$ is the equilibrium saturation ratio $\left(\frac{C_{\mathrm{g}}}{C^{*} \cdot \mathrm{KR}}\right)$ for size bin $j$, and $A$ and $B$ are adjustable parameters. $A$ is the threshold SR that controls 

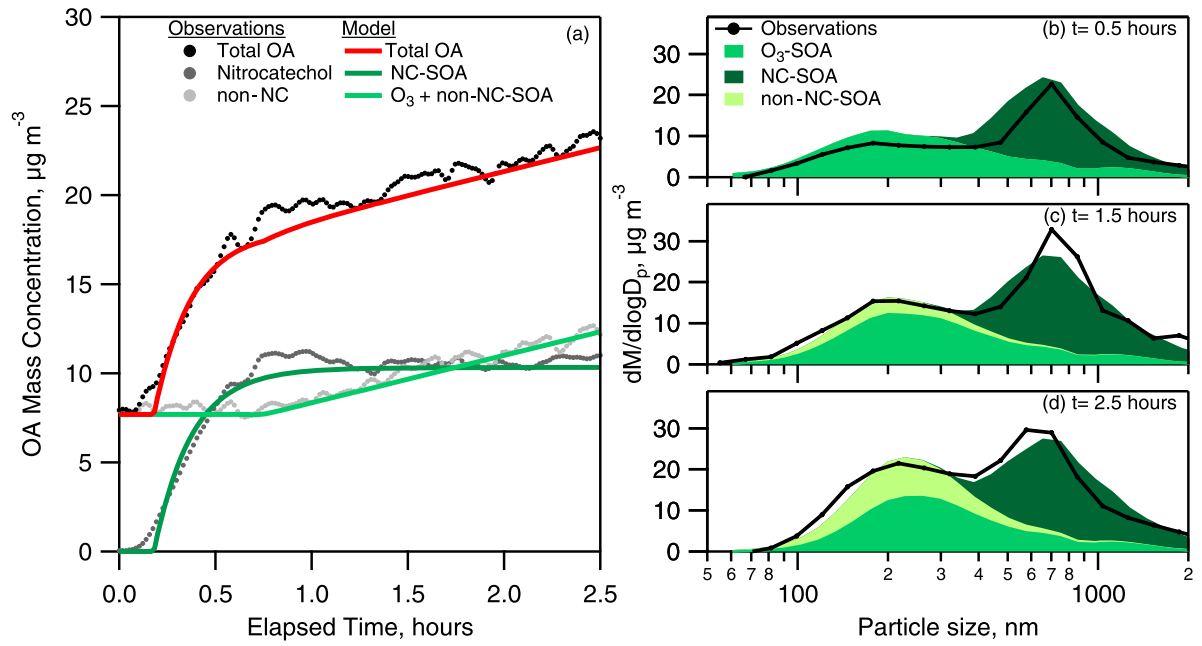

Figure 5. Model-measurement comparison for (a) $\mathrm{OA}$ mass concentrations and (b-d) OA mass size distributions for the catechol $+\mathrm{O}_{3}+\mathrm{NO}_{3}$ experiment at different time steps, where in the model, $t=0$ marks the addition of $\mathrm{NO}_{2}$ to form $\mathrm{NO}_{3}$. The observed AMS particle size is the vacuum aerodynamic diameter and the model size is converted to match.

the minimum particle size that activates and $B$ determines the width of the sigmoid, with a larger $B$ value producing a sharper sigmoid (as $B$ approaches infinity, heterogeneous nucleation approaches a step function as a function of the SR). $C_{\mathrm{g}}$ and $C^{*}$ are the gas-phase and saturation concentrations of NC-SOA in $\mu \mathrm{g} \mathrm{m}^{-3}$ and $\mathrm{KR}$ is the Kelvin ratio $\mathrm{KR}=\exp \left(\frac{\gamma \mathrm{MW}}{\rho R T d_{p, j}}\right)$, where $\gamma$ is the surface tension $\left(0.079 \mathrm{~N} \mathrm{~m}^{-1}\right),{ }^{31} \rho$ is the particle density $\left(1400 \mathrm{~kg} \mathrm{~m}^{-3}\right), R$ is the universal gas constant $\left(8.314 \mathrm{~J} \mathrm{~mol}^{-1}\right.$ $\left.\mathrm{K}^{-1}\right), T$ is the chamber temperature $(298 \mathrm{~K})$, and $d_{\mathrm{p}, j}$ is the particle diameter of size bin $j$ in $\mathrm{m}$.

Results from the SOM-TOMAS simulations are shown in Figure 5. Model predictions agreed with both the measured mass concentrations and mass size distributions for an A value or a threshold SR of $\sim 1.2(\sim 20 \%$ supersaturation required for heterogeneous nucleation). More specifically, the model reproduced the initial increase in NC-SOA and its nucleated condensation to form a second mode in the particle mass size distribution. Subsequently, the model reproduced the increase in non-NC-SOA mass and its condensation on the smaller mode that offered a larger surface area for condensation. Sensitivity simulations were performed with vapor or particle wall losses, changes in $C^{*}$ of NC-SOA, and phase-state assumptions for the existing $\mathrm{OA}$ but none of these altered the findings presented in Figure 5.

Chemical Drivers of Heterogeneous Nucleation. Immiscibility or activity, along with the Kelvin effect, is one potential source of the necessary barrier to the initial uptake of nitrocatechol, as nitrocatechol and the ozone oxidation products may be sufficiently different in chemical properties that nitrocatechol is not thermodynamically favored to absorb into pre-existing ozone oxidation products. Our observations, at low RH, are consistent with the idea that aerosol populations can evade mixing if the chemical properties are sufficiently different. If we take the elemental ratios to indicate the level of oxidation and a proxy for intermolecular forces, we see differences in the $\mathrm{O}_{3}$-derived SOA and nitrocatechol. The initial catechol ozonolysis produced SOA with an elemental oxygen-to-carbon ratio of $\mathrm{O} / \mathrm{C}=0.91$ and an elemental hydrogen-to-carbon ratio of $\mathrm{H} / \mathrm{C}=1.17$ that ages further in the chamber. This contrasts with the final mixed SOA products having an overall $\mathrm{O} / \mathrm{C}=0.70$ and $\mathrm{H} / \mathrm{C}=1.06$. While nitrocatechol has a relatively lower $\mathrm{O} / \mathrm{C}$ of 0.67 and $\mathrm{H} / \mathrm{C}$ of 1.0, oxygen atoms connected to heteroatoms should not be considered for the carbon oxidation state, so the adjusted $\mathrm{O} / \mathrm{C}$, only considering oxygen atoms connected to carbon and hydrogen atoms, is 0.3 . Phase separation of different organic components has been connected to differences in the oxidation state of those components. ${ }^{32,33}$ In comparing nitrocatechol partitioning in the FIGAERO-CIMS, we found that $\geq 96 \%$ of nitrocatechol is found in the particle phase under atmospheric conditions, which is consistent with a previously reported value of $96 \%{ }^{15}$ Nitrocatechol is favored to be in the particle phase for the conditions of the experiment, but the existing OA from the ozonolysis of catechol prevents condensation to those particles.

In addition to immiscibility, particle-phase diffusion limitations may also prevent the initial uptake of nitrocatechol on experimental timescales, leading to supersaturated nitrocatechol and heterogeneous nucleation. Viscosity measurements of the catechol $+\mathrm{O}_{3} \mathrm{SOA}$, using a poke-flow technique, ${ }^{34}$ as described in the Supporting Information, show that the viscosity of the catechol $+\mathrm{O}_{3}$ SOA under dry conditions is greater than $3 \times 10^{8} \mathrm{~Pa} \mathrm{~s}$, which is greater than the viscosity of tar pitch. ${ }^{35}$ This viscosity corresponds to a diffusion coefficient of below $2 \times 10^{-17} \mathrm{~cm}^{2} \mathrm{~s}^{-1}$ and characteristic molecular diffusion mixing time greater than $150 \mathrm{~h}$ for $D_{\mathrm{p}}=200 \mathrm{~nm}$ SOA particles, representing a clear barrier to the incorporation of nitrocatechol by gas-particle equilibrium partitioning.

One or both of the two limitations above (immiscibility and particle-phase diffusivity) create a barrier to net condensation, such that nitrocatechol becomes supersaturated and nucleates to form an independent mode on the surface of the existing aerosol, favored to larger particle sizes due to the Kelvin effect. Additional nitrocatechol, through equilibrium, net partitions exclusively on this mode containing nitrocatechol and not necessarily the mode with the largest surface area or volume. We suspect that heterogeneous nucleation occurred in the $\mathrm{O}_{3}$ $+\mathrm{NO}_{3}$ experiment but not the $\mathrm{OH} / \mathrm{NO}_{x}$ experiment because (1) the barriers (immiscibility or diffusion limitations) to condensation into the non-NC-SOA in the $\mathrm{O}_{3}+\mathrm{NO}_{3}$ experiment is higher than for the $\mathrm{OH} / \mathrm{NO}_{x}$ experiment and 
(2) nitrocatechol co-condenses with the multitude of other products in the catechol $+\mathrm{OH} / \mathrm{NO}_{x}$ oxidation while nitrocatechol is clearly the dominant product for the catechol $+\mathrm{NO}_{3}$ oxidation.

Future experiments targeted at isolated reactions may yield insights into the role of phase for these reactions. Finewax et al. ${ }^{15}$ used $\mathrm{N}_{2} \mathrm{O}_{5}$ as a source for $\mathrm{NO}_{3}$, and they make no note of unexpected size distributions in their SMPS data used to calculate aerosol volume concentrations, indicating that the ozonolysis of catechol is critical to the results of the experiment presented here. Direct ozonolysis of catechol without seed would change the size distribution of the existing aerosol upon $\mathrm{NO}_{3}$ oxidation and nitrocatechol production. Such an experiment might help address the question of phase for ozonolysis chemistry.

Implications for Chamber Studies and the Atmosphere. The observation that SOA growth bifurcates into distinct branches with differing growth rates, thus becoming separate particle populations centered about different diameters, has also been seen in $\mathrm{NO}_{2}+\mathrm{O}_{3}+$ monoterpene systems in a smaller $400 \mathrm{~L}$ Teflon chamber; Draper et al. ${ }^{36}$ describes the chamber and general methods. Specifically, for the highconcentration chamber oxidation of $\Delta$-carene $(\sim 300 \mathrm{ppb})$ by $\mathrm{O}_{3}(\sim 500 \mathrm{ppb})+\mathrm{NO}_{2}(\sim 300 \mathrm{ppb})$, at $\mathrm{RH}=30 \%$ and in the absence of seed aerosol, two distinct particle populations were observed (Figure 6), suggesting a similar thermodynamic or

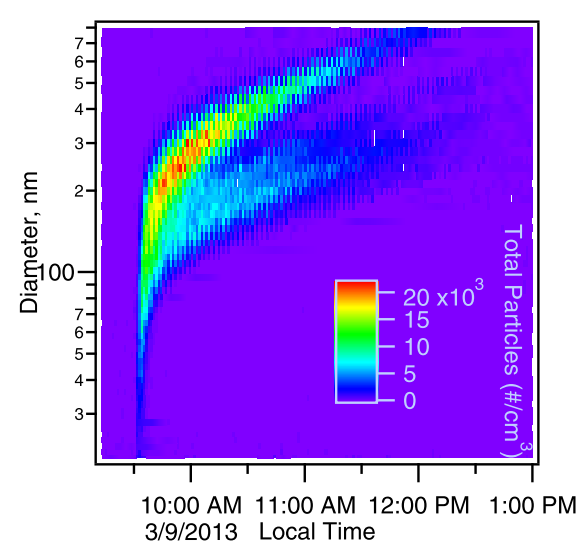

Figure 6. Brechtel scanning electrical mobility spectrometer measurements of particle size distributions over time in a darkened $400 \mathrm{~L}$ Teflon chamber upon the oxidation of $\Delta$-carene $(\sim 300 \mathrm{ppb})$ by a mix of $\mathrm{O}_{3}(\sim 325 \mathrm{ppb})$ and $\mathrm{NO}_{2}(\sim 450 \mathrm{ppb})$.

kinetic barrier to cross-condensation of the sub-sets of products, perhaps due to varying functionalization. In these flow-through chamber experiments, $\Delta$-carene was added to a chamber containing stabilized concentrations of $\mathrm{O}_{3}$ and $\mathrm{NO}_{2}$, producing a rapid homogeneous nucleation (new particle formation) event followed by growth. Under these conditions, $\mathrm{N}_{2} \mathrm{O}_{5}$ builds up as a $\mathrm{NO}_{3}$ radical reservoir prior to terpene injection, so that most oxidation proceeds via $\mathrm{NO}_{3}$ oxidation. Scanning electron microscopy and size-resolved chemical composition revealed that these two modes are chemically and morphologically distinct, with the larger size mode being more oxidized and more spherical (liquid-like) than the smaller mode. Thus, while this experiment used a flow tube and no seed rather than a static chamber with seed, we observe a similar bifurcation of OA.

Dual oxidation of catechol and $\Delta$-carene by $\mathrm{O}_{3}$ and $\mathrm{NO}_{3}$ produces unexpected bimodal size distributions in completely different experiments, indicating that different oxidation pathways can lead to a mixture of products that segregate into two distinct size modes. These experiments counter the common assumptions of homogeneous mixing of SOA products, equilibrium gas-particle partitioning, and kinetic condensation. For the organic-on-organic heterogeneous nucleation proposed here, VOCs are oxidized to semivolatile products that are thermodynamically or kinetically unfavored to condense onto existing OA. Therefore, vapor accumulates to concentrations beyond the equilibrium vapor pressure of the pure species until, at some threshold, the vapor nucleates a new phase on top of the existing aerosol but does not mix into the existing aerosol. The additional Kelvin (curvature) barrier is lower for larger particles compared to smaller particles, so that nucleation preferentially occurs on larger particles in the existing size distribution. A size-resolved chemistry and microphysics model (SOM-TOMAS) reproduced the OA size distribution of catechol $+\mathrm{O}_{3}+\mathrm{NO}_{3}$ using a heterogeneous nucleation mechanism to form a new phase on the existing aerosol. The model also captures the growth of the non-NCSOA by surface area-driven condensation of non-nitrocatechol products. Heterogeneous nucleation of organic vapors onto distinct OA greatly depends on the identity and properties of the existing SOA and condensable vapor, and, likely, the ambient conditions (e.g., temperature and relative humidity). The formation of SOA via heterogeneous nucleation can change size distributions in ways that will not be fully captured by models or bulk measurements, with important implications for their impact on air quality and climate. However, the extent to which this happens in the atmosphere is unclear due to the dearth of size-resolved chemical measurements of ambient aerosols and that subtle changes in the overall size distribution may not be easily observed given the large variety and overall mass of the existing primary and secondary OA. Additionally, distinct aerosol compositions needed to produce the large supersaturations needed for this mechanism may be difficult to achieve outside of an environmental chamber. Nevertheless, the impact of aerosol microphysics in this system suggests that SOA yields and rates derived from measurements of specific precursors onto specific aerosol populations may not reflect the full range of possible SOA yields or rates. In other words, the differences in behavior between the catechol $+\mathrm{O}_{3}+\mathrm{NO}_{3}$ and catechol $+\mathrm{OH} / \mathrm{NO}_{x}$ reactions suggest that condensation can depend on the identity of both the pre-existing population of aerosol as well as the presence of co-condensed species so that SOA yields/rates are not additive, as noted by a number of studies 9,37 Consideration of this possible method of condensation will be important in future experimental design-to either probe the influence of pre-existing aerosol on condensation processes or to avoid the influence of unexpected heterogeneous condensation. Condensation of organic vapors onto $\mathrm{OA}$ via heterogeneous nucleation offers a previously under considered pathway for condensation that does not follow diffusion-limited equilibrium partitioning and produces unexpected aerosol size distributions.

\section{ASSOCIATED CONTENT}

\section{Supporting Information}

The Supporting Information is available free of charge at https://pubs.acs.org/doi/10.1021/acs.est.1c02984. 
Information about instrumentation, chamber experiments, model simulations, and viscosity measurements (PDF)

\section{AUTHOR INFORMATION}

\section{Corresponding Authors}

Lauren A. Garofalo - Department of Chemistry, Colorado State University, Fort Collins, Colorado 80523, United

States; orcid.org/0000-0001-7593-2580;

Email: Lauren.Garofalo@colostate.edu

Delphine K. Farmer - Department of Chemistry, Colorado State University, Fort Collins, Colorado 80523, United States; (1) orcid.org/0000-0002-6470-9970;

Email: Delphine.Farmer@colostate.edu

\section{Authors}

Yicong He - Department of Mechanical Engineering, Colorado State University, Fort Collins, Colorado 80523, United States; 10 orcid.org/0000-0001-8969-1167

Shantanu H. Jathar - Department of Mechanical Engineering, Colorado State University, Fort Collins, Colorado 80523, United States; (1) orcid.org/0000-0003-4106-2358

Jeffrey R. Pierce - Department of Atmospheric Science, Colorado State University, Fort Collins, Colorado 80523, United States; 10 orcid.org/0000-0002-4241-838X

Carley D. Fredrickson - Department of Atmospheric Sciences, University of Washington, Seattle, Washington 98195, United States

Brett B. Palm - Department of Atmospheric Sciences, University of Washington, Seattle, Washington 98195, United States

Joel A. Thornton - Department of Atmospheric Sciences, University of Washington, Seattle, Washington 98195, United States; (1) orcid.org/0000-0002-5098-4867

Fabian Mahrt - Department of Chemistry, University of British Columbia, Vancouver, British Columbia V6T 1Z4, Canada; Laboratory of Environmental Chemistry, Paul Scherrer Institute, 5232 Villigen, Switzerland; 이이.org/ 0000-0002-7059-6765

Giuseppe V. Crescenzo - Department of Chemistry, University of British Columbia, Vancouver, British Columbia V6T 1Z4, Canada; 이이이.org/0000-0003-0936-3935

Allan K. Bertram - Department of Chemistry, University of British Columbia, Vancouver, British Columbia V6T 1Z4, Canada; orcid.org/0000-0002-5621-2323

Danielle C. Draper - Department of Chemistry, Reed College, Portland, Oregon 97202, United States; Division of Geological and Planetary Sciences, California Institute of Technology, Pasadena, California 91125, United States; () orcid.org/0000-0002-2027-8822

Juliane L. Fry - Department of Chemistry, Reed College,

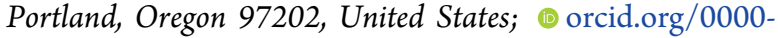
0003-1799-5828

John Orlando - National Center for Atmospheric Research, Boulder, Colorado 80307, United States

Xuan Zhang - National Center for Atmospheric Research, Boulder, Colorado 80307, United States; Department of Life and Environmental Sciences, University of California, Merced,

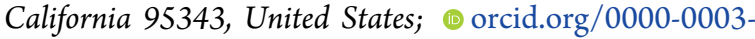
$1548-8021$

Complete contact information is available at: https://pubs.acs.org/10.1021/acs.est.1c02984

\section{Notes}

The authors declare no competing financial interest.

\section{ACKNOWLEDGMENTS}

This work is supported by National Oceanic and Atmospheric Administration (NOAA) Climate Program's Office Atmospheric Chemistry, Carbon Cycle, and Climate program (NA17OAR4310010). Y.H., S.H.J., and J.R.P. acknowledge support from the U.S. National Science Foundation (NSF; AGS-1950327), NOAA (NA17OAR4310001 and NA17OAR4310003), and DOE (DE-SC0017975). C.D.F., B.B.P., and J.A.T. acknowledge support from the U.S. National Science Foundation (NSF; AGS-1652688) and NOAA (NA17OAR4310012). A.K.B., G.V.C., and F.M. acknowledge support from the Natural Science and Engineering Research Council of Canada (grant RGPIN/04315-2014). F.M. acknowledges funding from the European Union's Horizon 2020 research and innovation program under the Marie Skłodowska-Curie grant agreement no. 890200. The National Center for Atmospheric Research is operated by the University Corporation for Atmospheric Research, under the sponsorship of the National Science Foundation. J.L.F. and D.C.D. thank Hyungu Kang assistance with experiments.

\section{REFERENCES}

(1) Pankow, J. F. An absorption model of gas/particle partitioning of organic compounds in the atmosphere. Atmos. Environ. 1994, 28, $185-188$.

(2) Donahue, N. M.; Robinson, A. L.; Stanier, C. O.; Pandis, S. N. Coupled partitioning, dilution, and chemical aging of semivolatile organics. Environ. Sci. Technol. 2006, 40, 2635-2643.

(3) Riipinen, I.; Pierce, J. R.; Yli-Juuti, T.; Nieminen, T.; Häkkinen, S.; Ehn, M.; Junninen, H.; Lehtipalo, K.; Petäjä, T.; Slowik, J.; Chang, R.; Shantz, N. C.; Abbatt, J.; Leaitch, W. R.; Kerminen, V.-M.; Worsnop, D. R.; Pandis, S. N.; Donahue, N. M.; Kulmala, M. Organic condensation: a vital link connecting aerosol formation to cloud condensation nuclei (CCN) concentrations. Atmos. Chem. Phys. 2011, 11, 3865-3878.

(4) Zhang, X.; Pandis, S. N.; Seinfeld, J. H. Diffusion-Limited Versus Quasi-Equilibrium Aerosol Growth. Aerosol Sci. Technol. 2012, 46, 874-885.

(5) Zaveri, R. A.; Shilling, J. E.; Zelenyuk, A.; Liu, J.; Bell, D. M.; D’Ambro, E. L.; Gaston, C. J.; Thornton, J. A.; Laskin, A.; Lin, P.; Wilson, J.; Easter, R. C.; Wang, J.; Bertram, A. K.; Martin, S. T.; Seinfeld, J. H.; Worsnop, D. R. Growth Kinetics and Size Distribution Dynamics of Viscous Secondary Organic Aerosol. Environ. Sci. Technol. 2018, 52, 1191-1199.

(6) Zaveri, R. A.; Shilling, J. E.; Zelenyuk, A.; Zawadowicz, M. A.; Suski, K.; China, S.; Bell, D. M.; Veghte, D.; Laskin, A. Particle-Phase Diffusion Modulates Partitioning of Semivolatile Organic Compounds to Aged Secondary Organic Aerosol. Environ. Sci. Technol. 2020, 54, $2595-2605$

(7) Shiraiwa, M.; Pöschl, U. Mass accommodation and gas-particle partitioning in secondary organic aerosols: dependence on diffusivity, volatility, particle-phase reactions, and penetration depth. Atmos. Chem. Phys. 2021, 21, 1565-1580.

(8) Fuchs, N. A.; Sutugin, A. G. High-dispersed aerosols. In Topics in Current Aerosol Research; Elsevier, 1971; p 1.

(9) Shilling, J. E.; Zawadowicz, M. A.; Liu, J.; Zaveri, R. A.; Zelenyuk, A. Photochemical Aging Alters Secondary Organic Aerosol Partitioning Behavior. ACS Earth Space Chem. 2019, 3, 2704-2716.

(10) Winkler, P. M.; Steiner, G.; Vrtala, A.; Vehkamäki, H.; Noppel, M.; Lehtinen, K. E. J.; Reischl, G. P.; Wagner, P. E.; Kulmala, M. Heterogeneous nucleation experiments bridging the scale from molecular ion clusters to nanoparticles. Science 2008, 319, 13741377. 
(11) Veres, P.; Roberts, J. M.; Burling, I. R.; Warneke, C.; de Gouw, J.; Yokelson, R. J. Measurements of gas-phase inorganic and organic acids from biomass fires by negative-ion proton-transfer chemicalionization mass spectrometry. J. Geophys. Res.: Atmos. 2010, 115, D23302.

(12) Stockwell, C. E.; Veres, P. R.; Williams, J.; Yokelson, R. J. Characterization of biomass burning emissions from cooking fires, peat, crop residue, and other fuels with high-resolution protontransfer-reaction time-of-flight mass spectrometry. Atmos. Chem. Phys. 2015, 15, 845.

(13) Olariu, R. I.; Klotz, B.; Barnes, I.; Becker, K. H.; Mocanu, R. FT-IR study of the ring-retaining products from the reaction of $\mathrm{OH}$ radicals with phenol, o-, m-, and p-cresol. Atmos. Environ. 2002, 36, 3685-3697.

(14) Berndt, T.; Böge, O. Gas-phase reaction of $\mathrm{OH}$ radicals with phenol. Phys. Chem. Chem. Phys. 2003, 5, 342-350.

(15) Finewax, Z.; de Gouw, J. A.; Ziemann, P. J. Identification and Quantification of 4-Nitrocatechol Formed from $\mathrm{OH}$ and $\mathrm{NO}_{3}$ Radical-Initiated Reactions of Catechol in Air in the Presence of NOx: Implications for Secondary Organic Aerosol Formation from Biomass Burning. Environ. Sci. Technol. 2018, 52, 1981-1989.

(16) Palm, B. B.; Peng, Q.; Fredrickson, C. D.; Lee, B. H.; Garofalo, L. A.; Pothier, M. A.; Kreidenweis, S. M.; Farmer, D. K.; Pokhrel, R. P.; Shen, Y. Quantification of organic aerosol and brown carbon evolution in fresh wildfire plumes. Proc. Natl. Acad. Sci. U.S.A. 2020, 117, 29469.

(17) Mayorga, R. J.; Zhao, Z.; Zhang, H. Formation of secondary organic aerosol from nitrate radical oxidation of phenolic VOCs: Implications for nitration mechanisms and brown carbon formation. Atmos. Environ. 2020, 244, 117910.

(18) Coeur-Tourneur, C.; Tomas, A.; Guilloteau, A.; Henry, F.; Ledoux, F.; Visez, N.; Riffault, V.; Wenger, J. C.; Bedjanian, Y. Aerosol formation yields from the reaction of catechol with ozone. Atmos. Environ. 2009, 43, 2360-2365.

(19) Tomas, A.; Olariu, R. I.; Barnes, I.; Becker, K. H. Kinetics of the reaction of $\mathrm{O}_{3}$ with selected benzenediols. Int. J. Chem. Kinet. 2003, $35,223-230$.

(20) Barnum, T. J.; Medeiros, N.; Hinrichs, R. Z. Condensed-phase versus gas-phase ozonolysis of catechol: A combined experimental and theoretical study. Atmos. Environ. 2012, 55, 98-106.

(21) Olariu, R. I.; Barnes, I.; Becker, K. H.; Klotz, B. Rate coefficients for the gas-phase reaction of $\mathrm{OH}$ radicals with selected dihydroxybenzenes and benzoquinones. Int. J. Chem. Kinet. 2000, 32, 696-702.

(22) Olariu, R. I.; Bejan, I.; Barnes, I.; Klotz, B.; Becker, K. H.; Wirtz, K. Rate coefficients for the gas-phase reaction of $\mathrm{NO} 3$ radicals with selected dihydroxybenzenes. Int. J. Chem. Kinet. 2004, 36, 577583.

(23) Zein, A. E.; Coeur, C.; Obeid, E.; Lauraguais, A.; Fagniez, T. Reaction Kinetics of Catechol (1,2-Benzenediol) and Guaiacol (2Methoxyphenol) with Ozone. J. Phys. Chem. A 2015, 119, 67596765.

(24) Farmer, D. K.; Matsunaga, A.; Docherty, K. S.; Surratt, J. D.; Seinfeld, J. H.; Ziemann, P. J.; Jimenez, J. L. Response of an aerosol mass spectrometer to organonitrates and organosulfates and implications for atmospheric chemistry. Proc. Natl. Acad. Sci. U.S.A. 2010, 107, 6670-6675.

(25) Bruns, E. A.; Perraud, V.; Zelenyuk, A.; Ezell, M. J.; Johnson, S. N.; Yu, Y.; Imre, D.; Finlayson-Pitts, B. J.; Alexander, M. L. Comparison of FTIR and Particle Mass Spectrometry for the Measurement of Particulate Organic Nitrates. Environ. Sci. Technol. 2010, 44, 1056-1061.

(26) Fry, J. L.; Kiendler-Scharr, A.; Rollins, A. W.; Wooldridge, P. J.; Brown, S. S.; Fuchs, H.; Dubé, W.; Mensah, A.; Dal Maso, M.; Tillmann, R.; Dorn, H.-P.; Brauers, T.; Cohen, R. C. Organic nitrate and secondary organic aerosol yield from $\mathrm{NO}_{3}$ oxidation of $\beta$-pinene evaluated using a gas-phase kinetics/aerosol partitioning model. Atmospheric Chemistry \& Physics 2009, 9, 1431-1449.
(27) Jayne, J. T.; Leard, D. C.; Zhang, X. F.; Davidovits, P.; Smith, K. A.; Kolb, C. E.; Worsnop, D. R. Development of an aerosol mass spectrometer for size and composition analysis of submicron particles. Aerosol Sci. Technol. 2000, 33, 49-70.

(28) Akherati, A.; He, Y.; Coggon, M. M.; Koss, A. R.; Hodshire, A. L.; Sekimoto, K.; Warneke, C.; de Gouw, J.; Yee, L.; Seinfeld, J. H.; Onasch, T. B.; Herndon, S. C.; Knighton, W. B.; Cappa, C. D.; Kleeman, M. J.; Lim, C. Y.; Kroll, J. H.; Pierce, J. R.; Jathar, S. H. Oxygenated aromatic compounds are important precursors of secondary organic aerosol in biomass-burning emissions. Environ. Sci. Technol. 2020, 54, 8568-8579.

(29) He, Y.; Akherati, A.; Nah, T.; Ng, N. L.; Garofalo, L. A.; Farmer, D. K.; Shiraiwa, M.; Zaveri, R. A.; Cappa, C. D.; Pierce, J. R.; Jathar, S. H. Particle Size Distribution Dynamics Can Help Constrain the Phase State of Secondary Organic Aerosol. Environ. Sci. Technol. 2021, 55, 1466-1476.

(30) He, Y.; King, B.; Pothier, M.; Lewane, L.; Akherati, A.; Mattila, J.; Farmer, D. K.; McCormick, R. L.; Thornton, M.; Pierce, J. R.; Volckens, J.; Jathar, S. H. Secondary organic aerosol formation from evaporated biofuels: comparison to gasoline and correction for vapor wall losses. Environ. Sci.: Processes Impacts 2020, 22, 1461-1474.

(31) Nitrocatechol-ChemSpider CSID:3864013. http://www. chemspider.com/Chemical-Structure.3864013.html (accessed Jan 21).

(32) Gorkowski, K.; Donahue, N. M.; Sullivan, R. C. Aerosol Optical Tweezers Constrain the Morphology Evolution of Liquid-Liquid Phase-Separated Atmospheric Particles. Chem 2020, 6, 204-220.

(33) Freedman, M. A. Phase separation in organic aerosol. Chem. Soc. Rev. 2017, 46, 7694-7705.

(34) Renbaum-Wolff, L.; Grayson, J. W.; Bateman, A. P.; Kuwata, M.; Sellier, M.; Murray, B. J.; Shilling, J. E.; Martin, S. T.; Bertram, A. $\mathrm{K}$. Viscosity of $\alpha$-pinene secondary organic material and implications for particle growth and reactivity. Proc. Natl. Acad. Sci. U.S.A. 2013, 110, 8014-8019.

(35) Koop, T.; Bookhold, J.; Shiraiwa, M.; Pöschl, U. Glass transition and phase state of organic compounds: dependency on molecular properties and implications for secondary organic aerosols in the atmosphere. Phys. Chem. Chem. Phys. 2011, 13, 19238-19255.

(36) Draper, D. C.; Farmer, D. K.; Desyaterik, Y.; Fry, J. L. A qualitative comparison of secondary organic aerosol yields and composition from ozonolysis of monoterpenes at varying concentrations of $\mathrm{NO}_{2}$. Atmos. Chem. Phys. 2015, 15, 12267-12281.

(37) Wang, Y.; Voliotis, A.; Shao, Y.; Zong, T.; Meng, X.; Du, M.; Hu, D.; Chen, Y.; Wu, Z.; Alfarra, M. R.; McFiggans, G. Phase state of secondary organic aerosol in chamber photo-oxidation of mixed precursors. Atmos. Chem. Phys. 2021, 21, 11303-11316. 